\title{
Ranking cloud render farm services for a multi criteria recommender system
}

\author{
J RUBY ANNETTE ${ }^{1, *}$ and AISHA BANU ${ }^{2}$ \\ ${ }^{1}$ Computer Science Engineering Department, Saveetha School of Engineering, Saveetha Institute of Medical \\ and Technical Sciences, Chennai 602 105, India \\ ${ }^{2}$ Computer Science Engineering Department, B.S.A Crescent Institute of Science and Technology, Chennai, \\ India \\ e-mail: rubysubash2010@gmail.com; aisha@bsauniv.ac.in
}

MS received 20 April 2018; accepted 7 July 2018; published online 17 December 2018

\begin{abstract}
Recommender systems that recommend ideal services or items to the online users are a very useful tool for both the users and the businesses. Usually for recommending services, multiple attributes of the services are evaluated and these types of recommender systems that evaluate multiple attributes are called multi criteria recommender systems. In these types of multi criteria recommender systems the ranking of services plays a major role. This work is focused on ranking the cloud render farm services which are of the PaaS (Platform-as-aService) type of cloud services that provide the entire platform for the animators to render the files using the cloud resources. This work identifies the Quality of Service (QoS) attributes that are important for the animators for selecting a cloud render farm service. The QoS values of four different real time cloud render farm services were collected by conducting real time experiments using the files of the "Big Buck Bunny", an open-source animated film project and were ranked using three Multi-Criteria Decision Making (MCDM) methods, namely the AHP (Analytical Hierarchical Process), TOPSIS (Technique for Order Preference by Similarity to the Ideal Solution) and SAW (Simple Additive Weighting). The analysis of the ranks obtained using the three different MCDM methods provide many useful insights and conclusions.
\end{abstract}

Keywords. Multi criteria decision making (MCDM); ranking; cloud services; render farm; recommender systems; multi criteria recommender system.

\section{Introduction}

Cloud computing technology provides scalable resources that could be obtained on demand [1-4]. The scalability of cloud resources according to the real time demand has made them popular for rendering animation files [5-10]. Cloud render farm services are PaaS (Platform-as-a-Service) type of cloud services that provide the entire platform for the animators to render the animation files using the cloud resources [11-16]. In order to render the animation files, the animator has to just schedule the frames that are to be rendered onto the render nodes of the chosen cloud render farm services. The advantage of rendering using cloud render farm services is that the number of render nodes can be scaled up or scaled down instantly based on the animator's requirements. As the animators have to pay only for the total number of rendering hours for which the cloud render farms were used, they can avoid investing in huge infrastructure required for the rendering purpose [16-20].

*For correspondence
During the selection of these cloud render farm services for rendering purposes, the animators check for multiple criteria like the cost, rendering speed, etc. and it becomes very difficult for them to compare and decide between the different choices of services. A multi criteria recommender system that makes use of the MCDM methods to evaluate the various alternatives and rank them based on the animator needs is a very useful tool in these situations.

Though, the MCDM methods have been used widely in recommenders of various application domains [21-23] to generate recommendations based on the evaluation of the multiple attributes or criteria requirements of the users. They have also been used for ranking the IaaS (Infrastructure-as-a-Service) type of general cloud services. However, these MCDM based multi criteria recommender system for PaaS (Platform-as-a-Service) type of cloud render farm services have not been considered. The contributions of this work are summarized as follows:

- This work analyzes and identifies the four Quality of Service (QoS) attributes that are specific to cloud 
render farm services and important to animators (section 2).

- A test bed was set-up and real time experiments were conducted using the files of the "Big Buck Bunny" project for collecting the real time Quality of Service (QoS) attributes values of four selected real time cloud render farm services (section 3).

- A case study was conducted using four different render farm services and the collected real time QoS attributes data collected were used to rank the four services using three different Multi-Criteria Decision Making (MCDM) methods namely, the AHP (Analytical Hierarchical Process), SAW (Simple Additive Weighting) and the TOPSIS (Technique for Order Preference by Similarity to the Ideal Solution) methods (section 4).

- The ranking obtained using these three different MCDM methods were compared and analyzed to gain useful insights and are discussed in detail (section 5).

- The related works are discussed in section 6 and the conclusions of the research work are provided in section 7 .

\section{Selection of QoS metrics and cloud render farm services}

The identification and selection of the important QoS metrics to be evaluated in selecting the cloud render farm services was an important step and it was carefully done after frequent discussion with the professional animators, freelancers and students. The four QoS metrics that were identified and selected are the following: (i) deadline adherence, (ii) pre-cost assessment accuracy, (iii) render node cost and (iv) functionality.

The deadline adherence measures the frequency of adherence or failure to render time deadline. The pre-cost assessment accuracy measures the frequency at which the services fail to assess pre-cost of rendering the files accurately. The other metric is the render node cost. The actual rendering cost is not stated explicitly in the websites. This work has explored the business models of many cloud render farm services to identify the indirect cost variables that may increase the render node cost significantly compared to the actual cost given in the websites. The other indirect cost variables identified are: (a) data storage, (b) activation time, use time, (c) software license, (d) data traffic incoming, and outgoing.

The last QoS attribute is the functionality, which is nothing but the additional utilities provided to the users to facilitate the rendering experience when using their services. The functionality of a service is measured in percentage and is defined as the number of functional features offered by the render farm service to the actual number of functional features desired by the animator. The functionality attributes identified includes; (a) particle and fluid dynamics caching, (b) custom shader/plug-in support, (c) FTP file transfer, (d) automatic scene analysis, (d) auto zip/RAR archiving, (e) real time preview, (f) unlimited free test renders, (g) texture/reference file detection, (h) multiple threading option, (i) file system cloning - 'Vroot', and (j) split -frame rendering.

\section{Test bed set-up and experiment for collecting QoS data}

A test bed was set-up for conducting the real time experiments by rendering the selected animation files in the cloud render farms selected. The animation files of different sizes from the "Big Buck Bunny" project was selected for conducting the real time cloud rendering. The "Big Buck Bunny" project is an open-source computer animated film that was created using the free Blender software by the Blender software development team. As the film has been created under the creative commons license, all the 3D models, texture and image files have been publicly released and are available as an open source. It contains over 400 files in 1.2 GB for the entire dataset and the files are organized into 13 scenes by top level folders under the project directory.

The final animation is for ten minutes and has more than 15,000 image files. The real time experiments were conducted in the Editorial VFX (Visual Effects) Suite in AVM Studio, Chennai and in Pax Animation Studio, Coimbatore. Three animation scenes with three different file sizes were selected for this purpose as given in table 1 . The selected small job is of $40 \mathrm{MB}$ and contains 28 frames, the medium job size is $90 \mathrm{MB}$ and contains 93 frames, whereas, the larger size job considered is about $290 \mathrm{MB}$ and contains 91 frames. It is interesting to note that though the file size of the large size job is huge, the total number of frames is less compared to the medium size job. The reason is that these frames may have more complex VFX scenes compared to the others. Hence, the job size is determined by the file size and is not based on the number of frames in the job. The three different files considered here were first rendered in the local rendering machines to estimate the average

Table 1. Details of animation scenes selected.

\begin{tabular}{lcccc}
\hline Job size & Scene & $\begin{array}{c}\text { No. of } \\
\text { frames }\end{array}$ & $\begin{array}{c}\text { Input } \\
\text { size } \\
(\mathrm{MB})\end{array}$ & $\begin{array}{c}\text { Avg. rendering time } \\
\text { (sec. per frame) }\end{array}$ \\
\hline Small & $\begin{array}{c}\text { 12.peach/ } \\
\text { 03.blend }\end{array}$ & 28 & 40 & 1260 \\
Medium & 01_intro/ \\
02.blend & 93 & 90 & 5837 \\
Large & $\begin{array}{c}\text { 02_rabbit/ } \\
\text { 02.blend }\end{array}$ & 91 & 290 & 9248 \\
& & & \\
\hline
\end{tabular}


rendering time (sec. per frame). The local rendering machines were of the configuration consisting of four CPU Cores (2.2 to $2.4 \mathrm{GHz}$ ), $4 \mathrm{~GB}$ RAM, minimum $50 \mathrm{~GB}$ of free hard disk space.

The selected files were rendered in four different render farm services that satisfy the functional requirements of the files and the real time QoS data were collected. The sample of functional requirement attributes is given in table 2. The four selected cloud render farm service are: (i) Render Rocket, (ii) Rebus Render farm, (iii) Rendering Fox and (iv) Ranch Computing. These four real time cloud render farm services were ranked based on four QoS attributes selected, namely Pre-Cost Assessment Accuracy, Functionality, Deadline Adherence and the Render node cost using three MCDM ranking methods selected, namely the AHP (Analytical Hierarchical Process), SAW (Simple Additive Weighting) and TOPSIS (Technique for Order Preference by Similarity to the Ideal Solution). The AHP method is selected as it has been already used to rank the general IaaS cloud services [21]. The SAW method was selected as it is considered the clearest and simplest method. Whereas, the TOPSIS method was selected as it has a logical approach to solving the MCDM problems.

\section{Case study: ranking the selected cloud render farm services}

A case study was conducted and the ranks obtained using three chosen MCDM methods, namely AHP, SAW and TOPSIS were compared. The real time QoS data of four cloud render farms, namely the Render Rocket, Rebus Render farm, Rendering Fox and the Ranch Computing were ranked. The render farm are represented as (RF1RF4) but not in the order as may be stated anywhere in this

Table 2. Example of functional requirements of users.

\begin{tabular}{|c|c|}
\hline $\begin{array}{l}\text { Functional requirements } \\
\text { attribute name }\end{array}$ & Sample values \\
\hline $\begin{array}{l}\text { Compute Unit Type } \\
\text { provided }\end{array}$ & $\mathrm{CPU}$ \\
\hline $\begin{array}{l}\text { Supported Software License } \\
\text { Fees }\end{array}$ & $\begin{array}{c}\text { Provided by service provider and } \\
\text { Fees included }\end{array}$ \\
\hline $\begin{array}{l}\text { Job Management Software } \\
\text { requirement }\end{array}$ & Plug in type \\
\hline $\begin{array}{l}\text { Software support } \\
\text { requirements }\end{array}$ & Cinema 4D \\
\hline $\begin{array}{l}\text { Render Engine Software } \\
\text { requirements }\end{array}$ & Mental Ray \\
\hline Plugin requirements & FumeFX \\
\hline $\begin{array}{l}\text { Operating System } \\
\text { requirements }\end{array}$ & Mac \\
\hline Cost of Render Node & 0.60 Per core per hour \\
\hline
\end{tabular}

work. The four QoS criteria (Deadline Adherence, Pre-Cost Assessment Accuracy, Functionality and Render node cost) are indicated as X1, X2, X3 and X4, respectively.

Table 3 gives the decision matrix constructed based on the real time QoS values of the four render farms. The weights of the QoS attributes were given by the user as the preferences may vary for each user and the rendering job requirement. Based on the weights assigned to each QoS attribute six scenarios (S1-S6) were considered for ranking as given above in table 4 .

\subsection{AHP method of ranking}

The Analytic Hierarchy Process (AHP) method of ranking has three or four phases/levels [24, 25]. The first level is to specify the overall goal, the QoS attributes and sub-attributes and the cloud render farm service alternatives as a hierarchical diagram as given in figure 1. In the first level the overall goal is identified as selecting the best cloud render farm services. The second level identifies and defines the four QoS criteria identified, namely Render Node Cost, Functionality, Deadline Adherence or the SLA accuracy and the Pre-Cost Assessment Accuracy. If any sub-criteria are considered then they form the third level, however, as only the four main QoS criteria are considered in this work, the cloud render farm service alternatives indicated as (RF), forms the third layer.

After identifying the overall goal in the first level, in the second level the QoS relative weighting is computed by obtaining the relative importance of QoS attribute in the range of 1 to 9 from the user. Since the relative weighting method is used in this work there is no need to normalize the QoS attribute weights, however, the sum of all QoS attributes weights assigned should be equal to one as given in table 4. To compute the relative ranking, the Eigenvector value is computed from the lower level QoS attribute values [24, 25]. For example, the Relative Ranking Matrix of the Functionality QoS attribute is computed first as in table 5 .

The values of the Relative Ranking Vector RRV3 (Functionality) for the Functionality QoS attributes are computed as,

Table 3. Decision matrix (D) for SAW, AHP and TOPSIS.

\begin{tabular}{lrrrr}
\hline Alt./Crit. & X1 & X2 & X3 & X4 \\
\hline RF1 & 99 & 98 & 100 & 0.45 \\
RF2 & 98 & 100 & 90 & 0.40 \\
RF3 & 100 & 89 & 80 & 0.35 \\
RF4 & 98 & 90 & 60 & 0.30 \\
\hline
\end{tabular}


Table 4. QoS attribute weights for SAW, AHP and TOPSIS.

\begin{tabular}{lllll}
\hline & \multicolumn{4}{c}{ Attributes (criteria) } \\
\cline { 2 - 5 } Weight (w) & $\mathrm{X} 1$ & $\mathrm{X} 2$ & $\mathrm{X} 3$ & $\mathrm{X} 4$ \\
\hline $\mathrm{w}$ (S1) & 0.25 & 0.25 & 0.25 & 0.25 \\
w(S2) & 0.1 & 0.1 & 0.1 & 0.7 \\
w(S3) & 0.1 & 0.1 & 0.4 & 0.4 \\
w(S4) & 0.3 & 0.1 & 0.3 & 0.3 \\
w(S5) & 0.1 & 0.5 & 0.1 & 0.3 \\
w(S6) & 0.7 & 0.1 & 0.1 & 0.1 \\
\hline
\end{tabular}

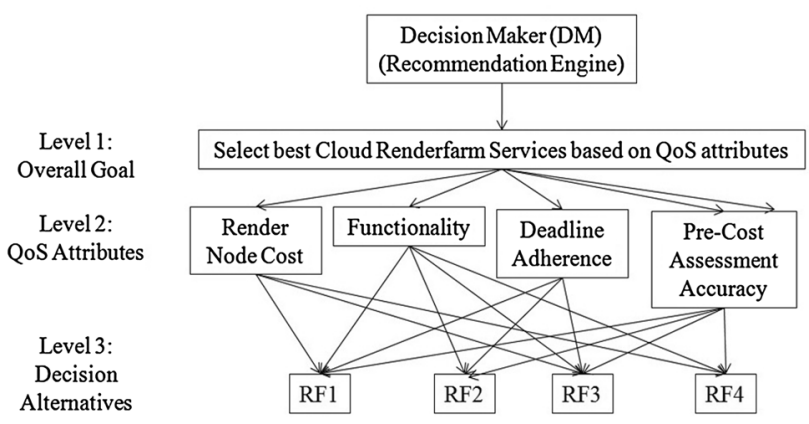

Figure 1. AHP hierarchy diagram of QoS attributes.

RRV3 (Functionality) $=[0.3005,0.2705,0.2405,0.1803]$

Similarly, the Relative Ranking Vector of the other QoS attributes is also calculated,

RRV1 (Deadline Adherence $)=[0.251,0.248,0.253,0.248]$

$$
\begin{aligned}
& \text { RRV2 (Pre cost Assessment Accuracy) } \\
& \quad=[0.260,0.265,0.240,0.240]
\end{aligned}
$$

RRV4 (Render Node Cost $)=[0.204,0.229,0.262,0.305]$

The aggregated final relative ranking value is computed by aggregating the final relative ranking vector value computed for each render farm services (RF1 to RF4) for all six scenarios (S1-S6). It is the product of the Relative Ranking Vector value obtained in phase 3 and the weights assigned for the particular QoS attribute in the particular scenario as shown in table 5 (table 6).

The ranking value and the order represented as (R1-R4) for all the scenarios (S1-S6) is given below in table 11.

\subsection{SAW method of ranking}

The Simple Additive Weighting Method (SAW) is also referred by other names like the Weighted Linear
Table 5. Computing relative ranking of the selected QoS attributes.

\begin{tabular}{lcccc}
\hline & RF1 & RF2 & RF3 & RF4 \\
\hline RF1 & 1 & $100 / 90$ & $100 / 80$ & $100 / 60$ \\
RF2 & $90 / 100$ & 1 & $90 / 80$ & $90 / 60$ \\
RF3 & $80 / 100$ & $80 / 90$ & 1 & $80 / 60$ \\
RF4 & $60 / 100$ & $60 / 90$ & $60 / 80$ & 1 \\
\hline
\end{tabular}

Table 6. Computing final relative ranking vector.

\begin{tabular}{lccccccc}
\hline & RRV1 & RRV2 & RRV3 & RRV4 & & \\
\hline RF1 & 0.251 & 0.260 & 0.3005 & 0.204 & & & \\
RF2 & 0.248 & 0.265 & 0.2705 & 0.229 & $*\left[\begin{array}{llll}0.25 & 0.25 & 0.25 & 0.25\end{array}\right]$ \\
RF3 & 0.253 & 0.240 & 0.2405 & 0.262 & & & \\
RF4 & 0.248 & 0.240 & 0.1803 & 0.305 & & & \\
\hline
\end{tabular}

Table 7. Normalized decision matrix $\left(\mathrm{D}^{\prime}\right)$ for SAW.

\begin{tabular}{lllll}
\hline Alt./Crit. & X1 & X2 & X3 & X4 \\
\hline RF1 & 0.99 & 0.98 & 1 & 0.67 \\
RF2 & 0.98 & 1 & 0.90 & 0.75 \\
RF3 & 1 & 0.89 & 0.80 & 0.857 \\
RF4 & 0.98 & 0.90 & 0.60 & 1 \\
\hline
\end{tabular}

Combination Method, MADM, the Scoring Method and the Weighted Sum Method [26]. The first step in this method is the quantification of the QoS attribute values. In the second step the Decision Matrix ' $\mathrm{D}$ ' is constructed and the importance weights are obtained from the user as given in tables 1 and 2. In the third step the overall score $\left(S_{i}\right)$ is calculated for each alternative. The normalized rating $\left(\mathrm{r}_{\mathrm{ij}}\right)$ of the ith render farm for the jth criterion is multiplied with the relative importance value or weights $\left(\mathrm{W}_{\mathrm{j}}\right)$ to calculate the overall score. The sum of the product value of all the criteria gives the overall score $\left(\mathrm{S}_{\mathrm{i}}\right)$ as given in Eq. (1). However, for the benefit criterion like Deadline Adherence, Pre-Cost Assessment Accuracy, Functionality the normalized rating $\left(\mathrm{r}_{\mathrm{ij}}\right)$ is computed using Eq. (2)

Table 8. Normalized decision matrix $\left(\mathrm{D}^{\prime} / \mathrm{r}_{\mathrm{ij}}\right)$ for TOPSIS.

\begin{tabular}{lcclc}
\hline Alt./Crit. & X1 & X2 & \multicolumn{1}{c}{ X3 } & X4 \\
\hline RF1 & 0.5012 & 0.5190 & 0.6 & 0.5936 \\
RF2 & 0.4961 & 0.5291 & 0.54 & 0.5277 \\
RF3 & 0.5063 & 0.4708 & 0.4800 & 0.4617 \\
RF4 & 0.4961 & 0.4762 & 0.3571 & 0.3958 \\
\hline
\end{tabular}


Table 9. Normalised weighted matrix (V) for scenario 1 in TOPSIS method.

\begin{tabular}{lcclc}
\hline Alt./Crit. & X1 & X2 & \multicolumn{1}{c}{ X3 } & X4 \\
\hline RF1 & 0.1253 & 0.1298 & 0.15 & 0.1484 \\
RF2 & 0.1240 & 0.1323 & 0.135 & 0.1319 \\
RF3 & 0.1265 & 0.1177 & 0.12 & 0.1154 \\
RF4 & 0.1240 & 0.1191 & 0.0893 & 0.0989 \\
\hline
\end{tabular}

$$
S_{i}=\sum_{j=1}^{M} w_{j} r_{i j}
$$

The normalized rating of the cost criterion is computed using Eq. (3). Where ' $x_{i j}$ ' represents the original value of jth criterion of ith alternative.

$$
\begin{gathered}
r_{i j}=\frac{x_{i j}}{\max _{i} x_{i j}} \\
r_{i j}=\frac{1 / x_{i j}}{\max _{i}\left(1 / x_{i j}\right)}
\end{gathered}
$$

The calculated normalized rating $\left(\mathrm{r}_{\mathrm{ij}}\right)$ values are given in table 7. Where, RF1, RF2, RF3 and RF4 are the cloud render farm services. Whereas, $\mathrm{X} 1, \mathrm{X} 2, \mathrm{X} 3$ and $\mathrm{X} 4$

Table 10. Ideal solution $\left(\mathrm{S}^{+}\right)$and negative ideal solution $\left(\mathrm{S}^{-}\right)$ for scenario 1 .

\begin{tabular}{lcccc}
\hline Ids/Criteria & $\mathrm{X} 1$ & $\mathrm{X} 2$ & \multicolumn{1}{c}{$\mathrm{X} 3$} & $\mathrm{X} 4$ \\
\hline $\mathrm{S}^{*}$ & 0.1265 & 0.1323 & 0.135 & 0.1484 \\
$\mathrm{~S}^{-}$ & 0.1240 & 0.1177 & 0.0893 & 0.0989 \\
\hline
\end{tabular}

represent the Deadline Adherence, Pre-Cost Assessment Accuracy, Functionality and Render Node Cost attributes, respectively. The final ranking values are the sum of the product of the normalized rating $\left(r_{i j}\right)$ values in the $D^{\prime}$ Matrix and the corresponding weights as given in table 11 .

\subsection{TOPSIS method of ranking}

'TOPSIS' is the Technique for Order Preference by Similarity to the Ideal Solution [27]. In TOPSIS, a Decision Matrix (D) using the values of the attributes is constructed on the first stage and then using the formula given in Eq. (4), a normalized Decision Matrix $\left(\mathrm{D}^{\prime}\right)$ is derived from it as given in table 8.

$$
r_{i j}=\frac{x_{i j}}{\sqrt{\sum_{i=1}^{n} x_{i j}^{2}}}
$$

Then, the weighted normalized decision matrix $\left(\mathrm{v}_{\mathrm{ij}}\right)$ is computed using Eq. (5).

$$
\mathrm{V}_{\mathrm{ij}}=\mathrm{w}_{\mathrm{i}} * \mathrm{r}_{\mathrm{ij}}
$$

Where, ' $\mathrm{w}_{\mathrm{i}}$ ' is weight of 'ith' criterion. The normalized weight matrix (V) for scenario 1 is given in table 9.

The ideal and the negative-ideal solutions are determined in the third step, using Eq. (6).

$$
\begin{aligned}
& \mathrm{A}^{+}=\max _{\mathrm{j}}\left[\mathrm{v}_{\mathrm{ij}}\right]=\left[\mathrm{v}_{1}^{+}, \mathrm{v}_{2}^{+}, \ldots, \mathrm{v}_{\mathrm{i}}^{+}, \ldots, \mathrm{v}_{\mathrm{m}}^{+}\right] \\
& \mathrm{A}^{-}=\min _{\mathrm{i}}\left[\mathrm{v}_{\mathrm{ij}}\right]=\left[\mathrm{v}_{1}^{-}, \mathrm{v}_{2}^{-}, \ldots, \mathrm{v}_{\mathrm{i}}^{-}, \ldots, \mathrm{v}_{\mathrm{m}}^{-}\right]
\end{aligned}
$$

\begin{tabular}{|c|c|c|c|c|c|c|c|c|c|c|c|c|}
\hline \multirow[b]{3}{*}{ Alt/S } & \multicolumn{12}{|c|}{ MADM methods } \\
\hline & \multicolumn{4}{|c|}{ SAW } & \multicolumn{4}{|c|}{ TOPSIS } & \multicolumn{4}{|c|}{ AHP } \\
\hline & RF1 & RF2 & RF3 & RF4 & RF1 & RF2 & RF3 & RF4 & RF1 & RF2 & RF3 & RF4 \\
\hline \multirow[t]{2}{*}{$\mathrm{S} 1$} & 0.91 & 0.908 & 0.887 & 0.87 & 0.778 & 0.472 & 0.286 & 0.02 & 0.253 & 0.249 & 0.243 & 0.241 \\
\hline & $(\mathrm{R} 1)$ & (R2) & (R3) & (R4) & (R1) & (R2) & (R3) & (R4) & (R1) & (R2) & (R3) & (R4) \\
\hline \multirow[t]{2}{*}{ S2 } & 0.766 & 0.813 & 0.869 & 0.948 & 0.209 & 0.659 & 0.679 & 0.935 & 0.239 & 0.243 & 0.257 & 0.280 \\
\hline & $(\mathrm{R} 4)$ & (R3) & (R2) & (R1) & (R4) & (R3) & (R2) & (R1) & $(\mathrm{R} 4)$ & (R3) & $(\mathrm{R} 2)$ & (R1) \\
\hline \multirow[t]{2}{*}{ S3 } & 0.865 & 0.858 & 0.852 & 0.828 & 0.772 & 0.478 & 0.344 & 0.044 & 0.253 & 0.251 & 0.250 & 0.243 \\
\hline & $(\mathrm{R} 1)$ & $(\mathrm{R} 2)$ & (R3) & (R4) & $(\mathrm{R} 1)$ & (R2) & (R3) & (R4) & (R1) & (R2) & (R3) & (R4) \\
\hline \multirow[t]{2}{*}{ S4 } & $0 . \mathrm{B} 96$ & $0 . \mathrm{B} 64$ & 0.889 & 0.886 & 0.873 & 0.171 & 0.673 & 0.657 & 0.253 & 0.242 & 0.251 & 0.243 \\
\hline & (R1) & (R4) & (R2) & (R3) & (R1) & (R4) & (R2) & (R3) & (R1) & (R4) & (R2) & (R3) \\
\hline \multirow[t]{2}{*}{ S5 } & 0.89 & 0.913 & 0.865 & 0.882 & 0.471 & 0.771 & 0.04 & 0.351 & 0.253 & 0.254 & 0.246 & 0.248 \\
\hline & (R2) & (R1) & (R4) & (R3) & (R2) & (R1) & (R4) & (R3) & (R2) & (R1) & (R4) & (R3) \\
\hline \multirow[t]{2}{*}{ S6 } & 0.955 & 0.951 & 0.958 & 0.93 & 0.666 & 0.658 & 0.778 & 0.184 & 0.251 & 0.250 & 0.251 & 0.246 \\
\hline & (R2) & (R3) & (R1) & (R4) & (R2) & (R3) & (R1) & (R4) & (R2) & (R3) & (R1) & (R4) \\
\hline
\end{tabular}

In the fourth step, using Eq. (7), the separation of the alternative from the ideal solution is calculated, as given below.

Table 11. Comparison of cloud render farms ranking by AHP, SAW and TOPSIS. 


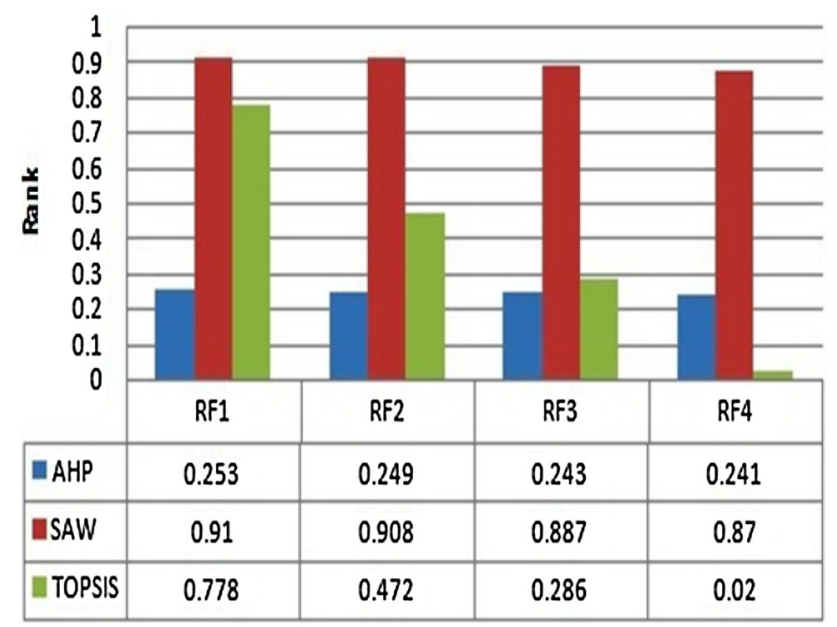

Figure 2. MCDM Ranking for Scenario 1.

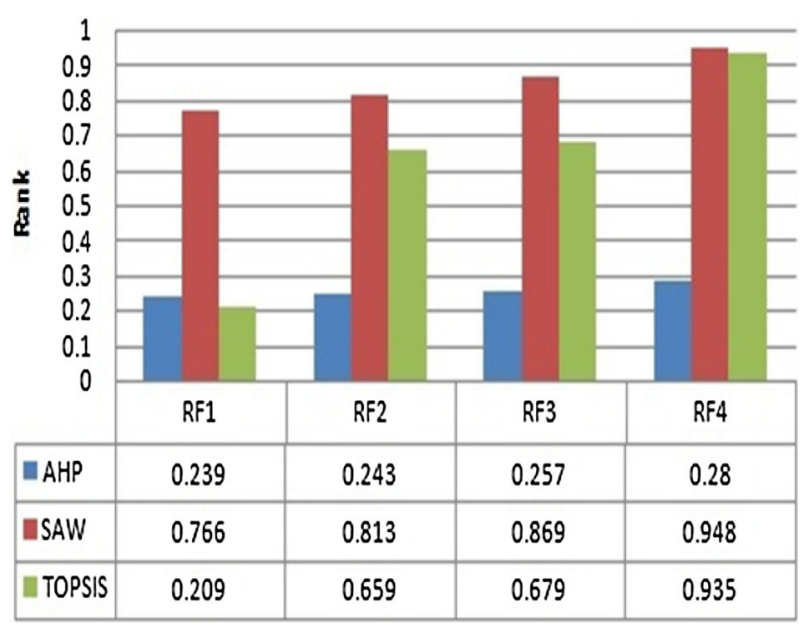

Figure 3. MCDM Ranking for Scenario 2.

$$
\mathrm{S}_{\mathrm{j}}^{+}=\sqrt{\sum_{\mathrm{i}=1}^{\mathrm{m}}\left(\mathrm{v}_{\mathrm{ij}}-\mathrm{v}_{\mathrm{i}}^{+}\right)^{2}}
$$

Also, using Eq. (8), the separation of each alternative from the negative-ideal solution is calculated as given below.

$$
\mathrm{S}_{\mathrm{j}}^{-}=\sqrt{\sum_{\mathrm{i}=1}^{\mathrm{m}}\left(\mathrm{v}_{\mathrm{ij}}-\mathrm{v}_{\mathrm{i}}^{-}\right)^{2}}
$$

The calculated values of the ideal Solution $\left(\mathrm{S}_{\mathrm{j}}^{+}\right)$and negative ideal solution $\left(S_{j}^{-}\right)$for scenario $(S 1)$ are given in table 10 .

The relative closeness between the alternative and the ideal solution $\left(A^{*}\right)$ is calculated using Eq. (9) and the alternatives are ranked based on the preference order.

$$
\mathrm{C}_{\mathrm{j}}=\frac{\mathrm{S}_{\mathrm{j}}^{-}}{\mathrm{S}_{\mathrm{j}}^{-}+\mathrm{S}_{\mathrm{j}}^{+}}
$$

\section{Results and discussion}

The ranking of the four render farm services (RF1-RF4) using the three MCDM methods for the six scenarios (S1S6) are compared with the help of table 11 and the Graphs (figures 2-7). It is clearly evident from the results, that the render farms are ranked in the same order irrespective of the MCDM method applied. However, the range of the ranking values differs for each method. The ranking value obtained for each render farm also differs significantly. Comparing the MCDM ranking of the render farms of Scenario $\mathrm{S} 1$ in figure 2, in which all the four attributes were assigned equal weights as given in table $4, \mathrm{RF} 1$ is ranked as the best alternative followed by RF2, RF3 and RF4 by all the three methods. Comparing the MCDM ranking of render farms in Scenario S3 (figure 4), in which more weightage were given to the accuracy and functionality attributes, RF1 is ranked as the best alternative. Moreover, even in the case of Scenario S4 given in figure 5, in which the lowest weight was assigned to the pre-cost assessment accuracy, RF1 is ranked as the best alternative. However, in Scenario S5, RF2 is ranked as the best alternative when the pre-cost assessment accuracy is assigned the highest priority as given in figure 6 . Scenario S2, in which the 'Functionality' attribute is assigned the highest priority, RF4 is ranked as the best as given in figure 3 , by all the three methods, followed by RF3, RF2 and RF1.

In Scenario S6, when more weight is assigned to the deadline adherence criteria, RF1 and RF3 both rank the best alternatives as given in figure 7 . Hence, from the results obtained, it is evident that the MCDM methods are highly

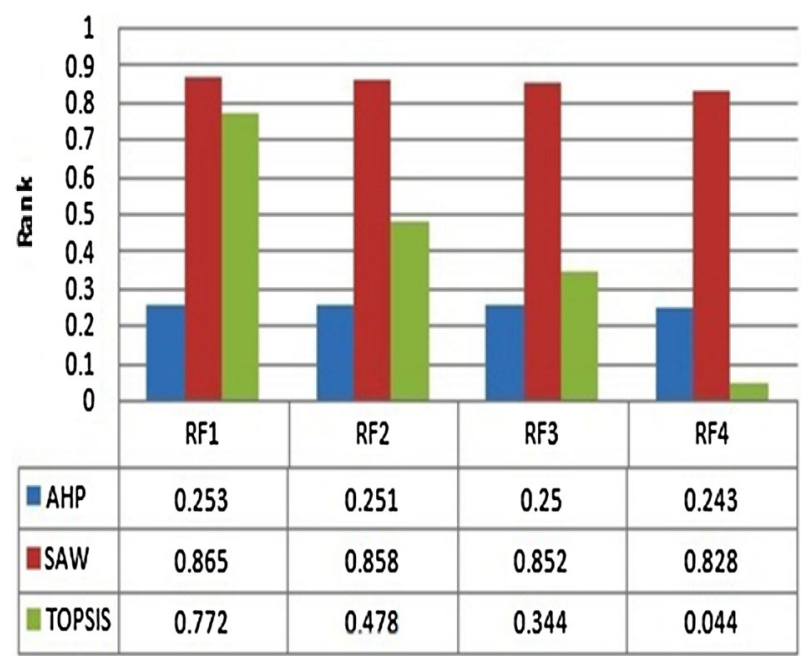

Figure 4. MCDM Ranking for Scenario. 


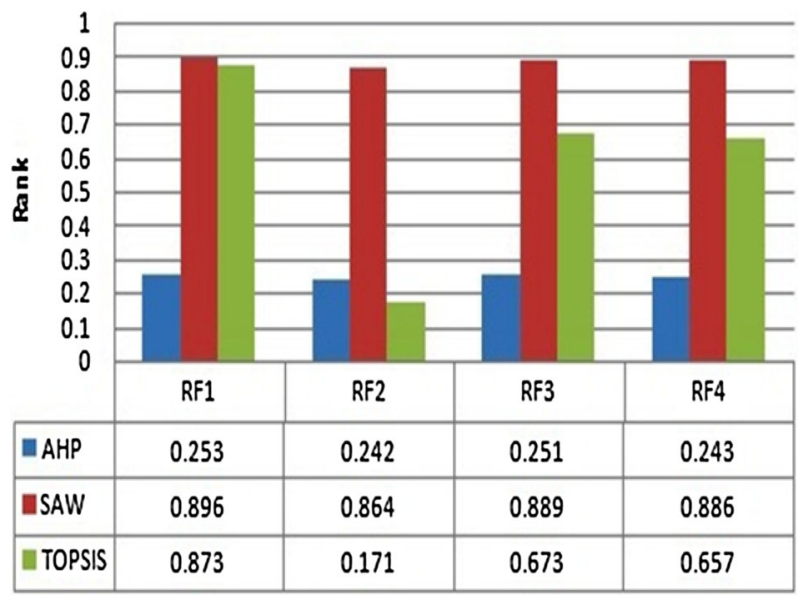

Figure 5. MCDM Ranking for Scenario 4.

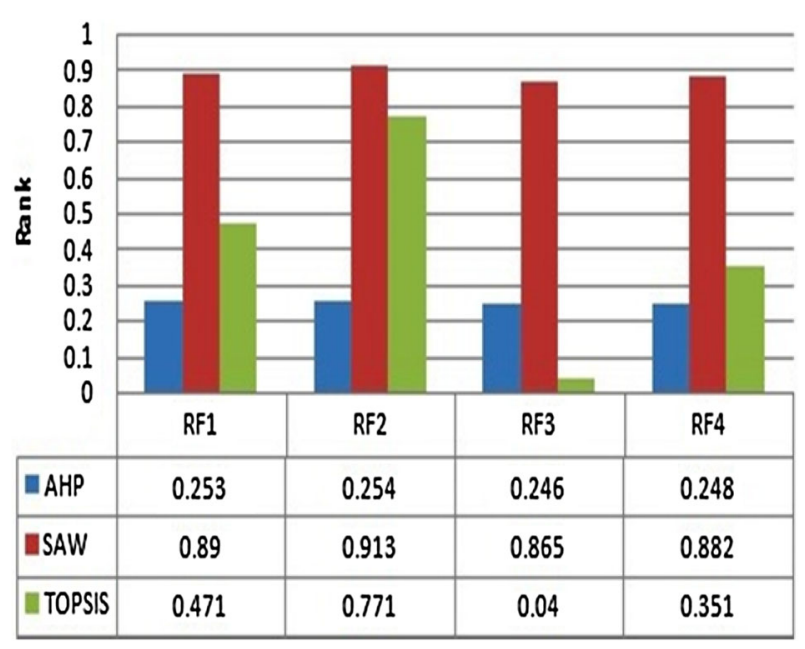

Figure 6. MCDM Ranking for Scenario 5.

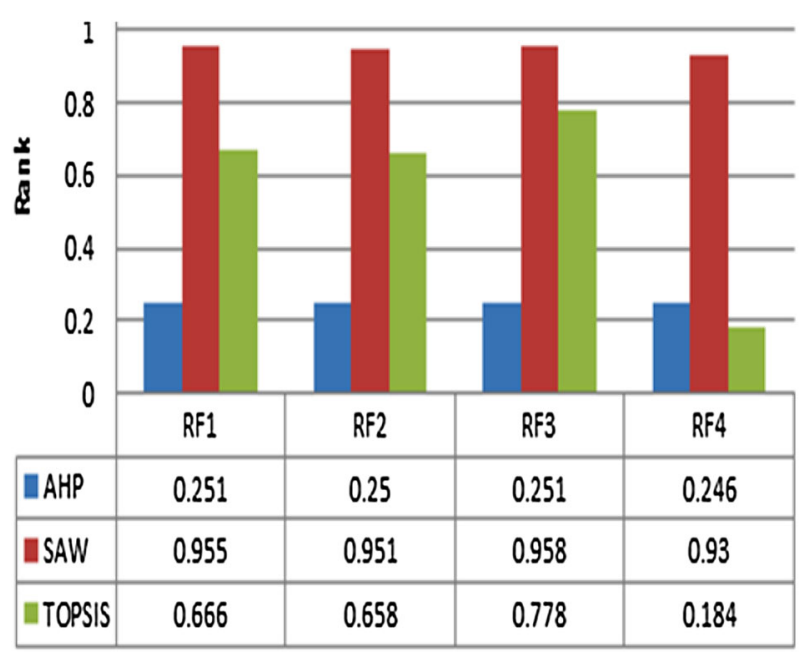

Figure 7. MCDM Ranking for Scenario 6. influenced by the weights assigned in selecting the best alternatives.

\section{Related work}

Many have worked towards ranking the cloud services. A QoS driven collaborative quality ranking framework for Cloud components is defined by [28]. This method proposes a greedy method for computing the component ranking based on the component preferences. Garg et al [29] defined the key performance indicators for QoS attributes and apply AHP based ranking. In their work, they defined some QoS attributes related to IaaS cloud services. Tran et al [30] proposed an AHP based ranking techniques for web services, considering the various quality of service attributes of web services. Pernici et al [31] proposed a novel approach for selecting adaptation strategies in service oriented systems based on fuzzy logic. They used hierarchical fuzzy inference systems for this purpose. Furthermore, Pernici et al [32] investigated an ANFIS-based learning model to provide optimized membership functions for each quality parameter to evaluate and predict the overall QoS of web services. Cheung et al [33] describes policies and defines their fitness degree using fitness functions which is compared with the current fuzzified context situations to infer adaptation decisions. The related works described above are focused on ranking the general Infrastructure-as-a-Service (IaaS) type of cloud services. However, ranking the domain specific Platform-as-a-Service (PaaS) type of services is difficult as identifying the right QoS attributes that measures the performance of the services is a challenge. Also, no other work has considered ranking the PaaS type of cloud render farm services. This work identifies four QoS attributes of cloud render farm services that are important to the animators and are also measured at the same time. The QoS attributes values are collected by conducting real time experiments and three MCDM methods like AHP, SAW and the TOPSIS methods are applied to the same set of QoS data to gain useful insights. The research works conducted to overcome the limitations of the E-commerce [34-36] like the trust, security and pricing issues $[37,38]$ lead to the evolution of new E-commerce models like cloud computing services. Similarly, more research works in the field of cloud render farms like [39-41] are required to overcome the limitations of the evolving cloud render farm services industry.

\section{Conclusion and future work}

This work ranks the four real time cloud render farm services using three popular MCDM methods. It also analyzes and identifies the four Quality of Service (QoS) attributes that are very specific to the cloud rendering services and 
important to animators. The real time Quality of Service (QoS) attributes values that were collected by conducting real time experiments using the files of the "Big Buck Bunny" project, which is an open-source animated film developed by the Blender Software team were used to rank four selected real cloud render farm services. Three different MCDM methods, namely the AHP, SAW and the TOPSIS methods were applied to rank these services. The ranking obtained using these three different MCDM methods were compared and analyzed to gain useful insights. It could be clearly seen from the results, that the render farms are ranked in the same order by all the three MCDM methods. However, it should be noted that the range of the ranking values of the render farms for each method differs and also the ranking value of each respective render farm obtained by applying the three different chosen MCDM methods differs. Moreover, the best alternative selected by the MCDM methods is highly influenced by the weights assigned to the QoS attributes. As a future work the ranking module would be incorporated into the recommendation framework and the recommendation of services based on their ranking obtained will be explored further.

\section{References}

[1] Liu F, Tong J, Mao J, Bohn R, Messina J, Badger L and Leaf D 2011 NIST Cloud Computing Reference Architecture. NIST Special Publication. 500: 292

[2] Armbrust M, Fox A, Griffith R, Joseph A D, Katz R, Konwinski A and Lee G 2010 A view of cloud computing. Commun. ACM 53: 50-58

[3] Buyya R, Yeo C, Venugopal S, Broberg J and Brandic I 2009 Cloud computing and emerging IT platforms: vision, hype, and reality for delivering computing as the 5th utility. Future Gener. Comput. Syst. 25: 99-616

[4] Cusumano M 2010 Cloud computing and SaaS as new computing platforms. Commun. ACM 53: 27-29

[5] Kennedy J and Healy P EP2538328 A1 [Patent] A method of provisioning a Cloud-based render farm

[6] Wilkiewicz J J and Hermes D J US20140094302 A1 [Patent] Cloud-based multi-player game play video rendering and encoding

[7] Madhavan K P C, Arns L L and Bertoline G R 2005 A distributed rendering environment for teaching animation and scientific visualization. Comput. Gr. Appl. 25: 32-38

[8] Wang S H, Li X Z and Zhang L 2013 The rendering system planning of the $3 \mathrm{~d}$ fashion design and store display based on cloud computing. Appl. Mech. Mater. 263: 3

[9] Crockett T W 1997 An introduction to parallel rendering. Parallel Comput. 23: 819-843

[10] Chalmers A, Davis T, Kato K and Reinhard E 2001 Practical parallel processing for today's rendering challenges. SIGGRAPH Course Notes 40: 32-38

[11] Toshi A C T A D, Reinhard K E and Antonio S 2002 Practical Parallel Rendering 53: 27-29
[12] Yao J, Pan Z and Zhang H 2009 A Distributed Render Farm System for Animation Production", Entertainment Computing-ICEC. Berlin: Springer, pp. 264-269

[13] Hong Z, Wang Y and Shi M 2011 SPN model-based performance of job scheduling plans for distributed rendering environment. In: International Conference on Multimedia Technology (IEEE), pp. 27-29

[14] Gooding S L, Arns L, Smith P and Tillotson J 2006 Implementation of a distributed rendering environment for the TeraGrid. In: Challenges of Large Applications in Distributed Environments (IEEE), pp. 13-22

[15] Gonzalez-Morcillo C, Weiss G, Vallejo D, Jimenez-Linares and Castro-Schez J J 2010 A multiagent architecture for 3D rendering optimization. Appl. Artif. Intell. 24: 313-349

[16] Tal D 2013 Rendering in SketchUp: from modeling to presentation for architecture, landscape architecture, and interior design. Hoboken: Wiley, pp. 41-43

[17] Siti Rashidah and Misrohim 2010 Implementation of Network Rendering Farm. Project Report, UTeM, pp. 52, 53

[18] Chong A, Sourin A and Levinski K 2006 Grid-based computer animation rendering. In: Proceedings of the 4th international conference on Computer graphics and interactive techniques, GRAPHITE '06. ACM

[19] Glez-Morcillo C, Vallejo D, Albusac J, Jiménez L and Castro-Schez J J 2011 A new approach to grid computing for distributed rendering. In: International Conference on $P 2 P$, Parallel, Grid, Cloud and Internet Computing (3PGCIC), IEEE.

[20] Patoli M Z, Gkion M, Al-Barakati A, Zhang W, Newbury P and White M 2009 An open source grid based render farm for blender 3d, Power Systems Conference and Exposition. PSCE'09. IEEE/PES

[21] Garg S K, Versteeg S and Buyya R 2011 SMICloud: a framework for comparing and ranking cloud services. In: Fourth IEEE International Conference on Utility and Cloud Computing (UCC), pp. 210-218

[22] Wang S, Zheng Z, Sun Q, Zou H and Yang F 2011 Cloud model for service selection. In: Computer Communications Workshops (INFOCOM WKSHPS), IEEE, pp. 666-671

[23] Hussain F K and Hussain O K 2011 Towards multi-criteria cloud service selection. In: Proceedings of the 2011 Fifth International Conference on Innovative Mobile and Internet Services in Ubiquitous Computing (IMIS), pp. 44-48

[24] Saaty T L 1990 How to make a decision: the analytic hierarchy process. Eur. J. Oper. Res. 48: 9-26

[25] Tran V Xuan, Tsuji H and Masuda R 2009 A new QoS ontology and its QoS-based ranking algorithm for Web services. Simul. Model. Pract. Theory 17: 1378-1398

[26] Afshari A, Mojahed M and Yusuff R M 2010 Simple additive weighting approach to personnel selection problem. Int. J. Innov. Manag. Technol. 1: 511

[27] García-Cascales M S and Lamata M T 2012 On rank reversal and TOPSIS method. Math. Comput. Model. 56: 123-132

[28] Zheng Z, Zhang Y and Lyu M R 2010 CloudRank: a QoS driven component ranking framework for cloud computing. In: Proceedings of the IEEE Symposium on Reliable Distributed Systems

[29] Garg S K, Versteeg S and Buyya R 2012 A framework for ranking of cloud computing services. Future Gener. Comput. Syst. 29: 1012-1023 
[30] Tran V X, Tsuji H and Masuda R 2009 A new QoS ontology and its QoS based ranking algorithm for Web services. Simul. Model. Pract. Theory 17: 8

[31] Perinici B and Siadat H 2011 Selection of service adaptation strategies based on fuzzy logic. In: Proceedings of the IEEE World Congress on Services, p. 4

[32] Pernici B and Siadat H 2011 Evaluating web service QoS: a neural fuzzy approach. In: Proceedings of the IEEE International Conference on Service-Oriented Computing and Applications (SOCA'11), USA, p. 2

[33] Cheung R, Cao J, Yao G and Chan A 2006 A fuzzy-based service adaptation middleware for context-aware computing. In: Proceedings of the International Conference on Embedded and Ubiquitous Computing, pp. 580-590

[34] Sengupta A, Mazumdar C and Barik M S 2005 e-Commerce security - a life cycle approach. Sadhana 30(2-3): $119-140$
[35] Patil V and Shyamasundar R K 2005 Trust management for e-transactions. Sadhana 30(2-3): 141-158

[36] Madanmohan T R 2005 Successful e-marketplaces: an institutional perspective. Sadhana 30(2-3): 431-444

[37] Raghavan N S 2005 Data mining in e-commerce: a survey. Sadhana 30(2-3): 275-289

[38] Rajaraman V 2005 Building blocks of e-commerce. Sadhana 30(2-3): 89-117

[39] Annette R and Banu A 2017 Multi Criteria Recommendation Engine for Cloud Render Farm Service. Chennai: B.S.A Crescent Institute of Science \& Technology

[40] Annette R and Banu W A 2014 A service broker model for cloud based render farm selection. Int. J. Comput. Appl. 96(24): 11-14

[41] Annette J R, Banu W A and Chandran P S 2015 Renderingas-a-service: taxonomy and comparison. Procedia Comput. Sci. 50: 276-281 